\title{
Ginseng Root
}

National Cancer Institute

\section{Source}

National Cancer Institute. Ginseng Root. NCI Thesaurus. Code C91402.

The aromatic root of perennial herbs of Panax ginseng. 